\title{
Динамика спектра динамических решеток в активной среде волоконного лазера с самосканированием частоты
}

\author{
И.А. Лобач ${ }^{1,2}$, Р.В. Дробышев ${ }^{1, *}$, Е.В. Подивилов ${ }^{1,2}$, С.И. Каблуков ${ }^{1,2}$ \\ ${ }^{1}$ Институт автоматики и электрометрии СО РАН \\ ${ }^{2}$ Новосибирский государственный университет \\ *E-mail: r.drobyshev@mail.ru
}

DOI:10.31868/RFL2018.59-60

Усиление и обратная связь определяют характеристики генерации в лазерных системах. Необычные лазерные характеристики наблюдаются, когда обратная связь в лазере в виде динамических решеток (ДР) показателя преломления и/или усиления формируется генерируемым излучением. В частности, было показано, что динамическая распределенная связь в волоконных лазерах приводит к регулярной динамике лазерной частоты - самосканированию частоты [1]. В подобных волоконных лазерах частота меняется скачкообразно между импульсами на частоту кратную частоте межмодовых биений резонатора. При этом каждый импульс может состоять из одной продольной моды [1]. Ранее свойства динамических решеток уже изучались. В частности, моделирование [2] и эксперимент [3] показывают, что ее коэффициент отражения может составлять $\sim 20-30 \%$ и $\sim 5-7 \%$ соответственно. Стоит отметить, что полученные ранее результаты по определению параметров ДР носят только оценочный характер. Данная работа посвящена как уточнению спектральных характеристик, так и получению временных характеристик ДР в волоконном лазере.

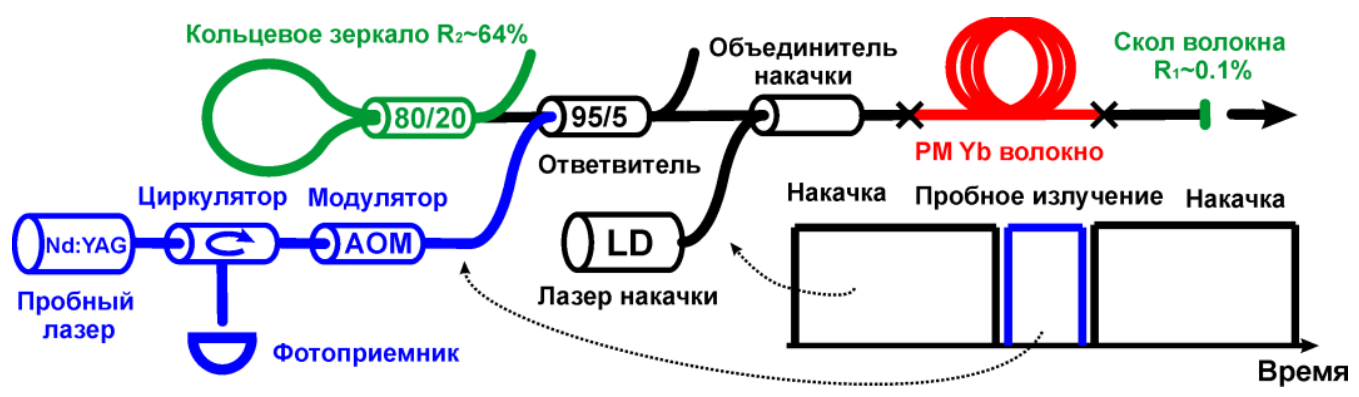

Рис. 1. Схема волоконного иттербиевого лазера и установки для измерения спектра отражения ДР.

Основная идея эксперимента заключается в измерении спектра ДР с помощью пробного перестраиваемого лазера в отсутствии накачивающего излучения. Ранее в работе [4] было показано, что уже сформированная ДР продолжает существовать даже в отсутствии накачивающего излучения до характерных времен $\sim 1$ мс в случае иттербиевой активной среды. ДР формировалась в работающем волоконном лазере с самосканированием частоты на основе иттербиевого волокна длиной 3 метра (Рис.1). Резонатор лазера был сформирован плотным кольцевым зеркалом и слабоотражающим торцом сколотого под малым углом волокна. В некоторый момент времени излучение накачки выключалось и включалось перестраиваемое по частоте (в диапазоне $\sim 150$ МГц) одночастотное пробное излучение. В эксперименте измерялась временная динамика интенсивности пробного излучения, отраженного от сформированной ДР. За время выключения накачки 200 мкс перестройка частоты пробного излучения повторялась порядка 20 раз, учитывая оба 
направления сканирования, по гармоническому закону с периодом 20 мкс. В случае, когда резонансная длина волны не совпадает с длиной волны пробного лазера наблюдается спадающий во времени уровень сигнала (Рис.2a), который соответствует отражению от резонатора волоконного лазера с усиливающей средой и слабым выходным зеркалом (Рис.1). Спад сигнала связан с уменьшением усиления сигнала в активной среде в отсутствии накачивающего излучения. При изменении длины волны генерации в лазере с самосканированием частоты, происходит также изменение длины волны отражения ДР. По этой причине, в некоторые момент времени происходит согласование частот пробного лазера и ДР, приводящее к увеличению добротности резонатора волоконного лазера и уровня сигнала, отраженного от резонатора. Наблюдается серия спадающих узких пиков большей амплитуды (Рис.2б). В этом случае резкий спад интенсивности связан как с конечным временем жизни ДР, так и с уменьшением коэффициента усиления. По причине периодического характера перестройки частоты пробного лазера все пики соответствуют спектру отражения одной и той же ДР, но измеренному в разные моменты времени.
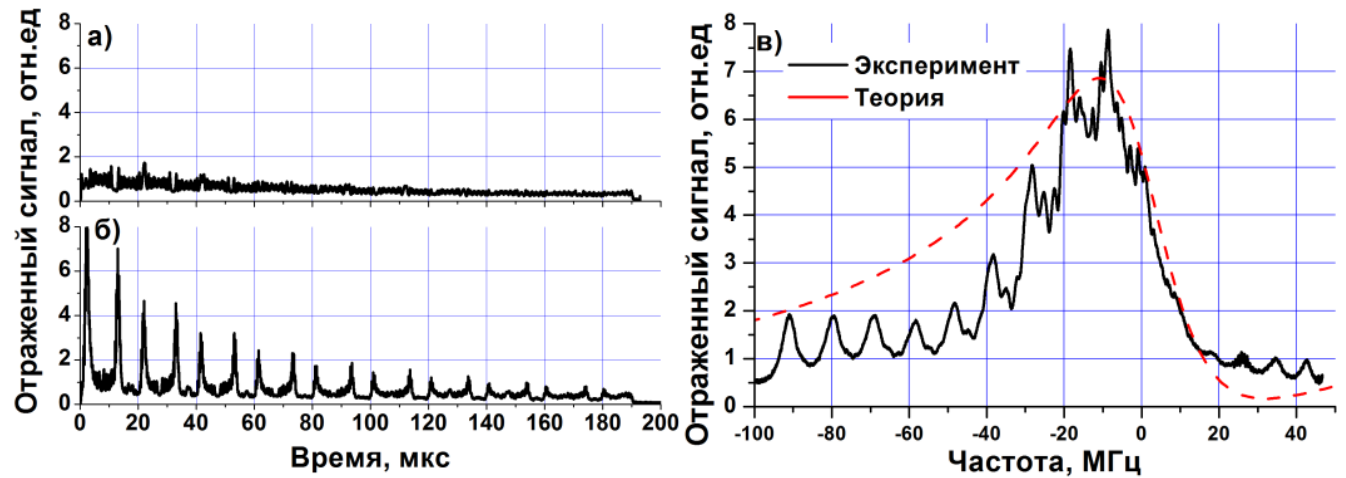

Рис.2. Временная динамика отраженного сигнала (а) вне и (б) в резонансе. Экспериментальный и теоретический спектр отражения динамической решетки сразу после выключения накачки.

Наибольший интерес представляет первый пик по причине наименьшего вклада процесса затухания в его амплитуду. Зная зависимость измерения частоты пробного излучения от времени, можно восстановить спектр отраженного сигнала (Рис.2в). Отраженный сигнал в резонансе нормировался на уровень сигнала вдали от резонанса, соответствующий известному коэффициенту отражения. Можно заметить, что в спектре наблюдается периодическая модуляция с периодом порядка 10 МГц, которая соответствует модовой структуре резонатора исследуемого лазера. Теоретический спектр отраженного сигнала без учёта влияния плотного зеркала волоконного лазера [3] также представлен на Рис.2б. Наилучшее согласие по амплитуде наблюдается при модуляции показателя ДР $4.5 \cdot 10^{-8}$, что в приближении однородной ДР соответствует коэффициенту отражения $\sim 15 \%$. Более детальное описание эксперимента по измерению отражения ДР, а также результатов моделирования будет представлено в докладе.

Работа выполнена при финансовой поддержке РНФ (грант 18-12-00243).

\section{Литература}

[1] I.A. Lobach, et al., Laser Physics Letters, 11, 045103 (2014)

[2] P. Peterka, et al., IEEE Journal of Selected Topics in Quantum Electronics 24, 3, 902608 (2018)

[3] I.A. Lobach, et al., Optics Letters 42, 4207-4210 (2017)

[4] R.V. Drobyshev, et al., 2016 International Conference Laser Optics, St. Petersburg, 2018, pp. R1-50, (2018) 